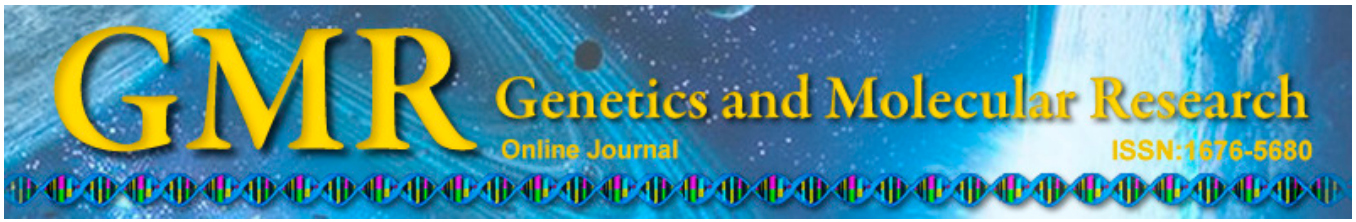

\title{
Genetic differences between the wild and hatchery-produced populations of Korean short barbeled grunter (Hapalogenys nitens) determined with microsatellite markers
}

\author{
H.S. An ${ }^{1}$, H.W. Kang ${ }^{1}$, H.S. Han ${ }^{1}$, J.Y. Park ${ }^{2}$, C.G. Hong ${ }^{2}$, J. Park ${ }^{1}$, \\ J.I. Myeong ${ }^{1}$ and C.M. $\mathrm{An}^{1}$ \\ ${ }^{1}$ Biotechnology Research Division, \\ National Fisheries Research and Development Institute, Busan, Korea \\ ${ }^{2}$ Aquaculture Industry Division, \\ Nacional Fisheries Research and Development Institute, Yeosu, Korea \\ Corresponding author: H.S. An \\ E-mail: hsan97@korea.kr
}

Genet. Mol. Res. 13 (4): 8901-8912 (2014)

Received May 14, 2014

Accepted September 25, 2014

Published October 31, 2014

DOI http://dx.doi.org/10.4238/2014.October.31.5

\begin{abstract}
Short barbeled grunter, Hapalogenys nitens, is an economically important fishery resource. In Korea, this fish is in the early stage of domestication, and it has been regarded as the candidate marine fish species for prospective aquaculture diversification. This study presents a preliminary investigation of the future viability of sustainable fry production from short barbeled grunter. We used 12 polymorphic nuclear microsatellite DNA loci to analyze the possible genetic variability between the wild and hatchery-produced populations of short barbeled grunter from Korea and identified 91 alleles. Compared to the wild population, significant genetic changes including reduced genetic diversity (average allele number: $7.42 \mathrm{vs}$ 3.75; average expected heterozygosity: 0.713 vs 0.598 , Wilcoxon signedrank test; $\mathrm{P}<0.05)$ and differentiation [overall fixation index $\left(F_{\mathrm{ST}}\right)=0.088$, $\mathrm{P}<0.01]$ occurred in the hatchery-produced population, as indicated by the
\end{abstract}


observation of allele richness, unique allele, heterozygosity, $F_{\mathrm{ST}}$, and results of molecular analysis of variance. These findings indicate that genetic drift may have promoted the differentiation between these 2 populations, which may have negative effects on sustainable fry production. Therefore, genetic variations of the wild and hatchery-produced populations should be monitored and subjected to control inbreeding through a commercial breeding program. The information presented by this paper would provide a useful genetic basis for future sustainable culturing planning and management of $H$. nitens.

Key words: Korean short barbeled grunter; Hapalogenys nitens; Genetic variability; Microsatellite loci

\section{INTRODUCTION}

The Korean short barbeled grunter, Hapalogenys nitens, belongs to the genus Hapalogenys (Perciformes: Haemulidae) and is distributed in the Northwest Pacific region, spanning Korea, Southern Sea of Japan, and East China Sea (NFRDI, 2004). H. nitens are bottom-feeding predators, and they have been named after their ability to produce a typical grunting sound by grinding their teeth (Johnson and Gill, 1998). In Korea, the annual catch of this fish has been very low; however, their high commercial value, robustness, and rapid growth ability even in overcrowded conditions makes them a good candidate species for aquaculture diversification (Kang et al., 2009). Thus, efforts have been initiated in the development of aquaculture for short barbeled grunter since the early 2000s. However, the complete culturing process required for sustainable fry production of short barbeled grunter, which includes reproduction control, captive spawning, hatching, and larval and juvenile rearing, is not yet established. It is therefore important to obtain genetic information about this fish species to rule out genetic variability within the hatchery-produced population as the reason for affecting the aquaculture process.

Aquaculture practices are likely to reduce the genetic diversity by founder effects, inbreeding, and random genetic drift in hatchery-reared stocks, and cultured fish stocks typically represent gene pools that are distinct from those of the natural populations (Allendorf and Ryman, 1987; Wang et al., 2011). Lack of genetic variation may lead to potentially harmful effects on the various commercially important traits such as disease resistance, environmental adaptability, and growth, which would impair efficient aquaculture (Allendorf and Phelps, 1980). For this reason, some research focused on genetic monitoring of the differences between hatchery stocks and wild populations in various fish species (Sekino et al., 2002; Kohlmann et al., 2005). The maintenance of genetic diversity in hatchery-produced populations has been also reported for other marine organisms (Pan and Yang, 2010). Molecular genetic diversity in fish has been reported to be associated with life history traits that reflect habitat types (DeWoody and Avise, 2000); therefore, it is necessary to investigate genetic variability in the wild and hatchery-produced populations of short barbeled grunter to accumulate significant scientific data fundamental to the success of aquaculture development strategies. Unfortunately, despite the importance of short barbeled grunter for commercial aquaculture and the concerted efforts aimed toward the development of aquaculture in Korea, no information is yet available on the genetic variation between and within the wild and hatchery-produced populations of this species. 
Molecular markers have proven to be an exceptional indicator of genetic variation within and between populations of many fishery animals (Choi and Kim, 2012; Hong et al., 2012; Lee and Hur, 2012). Among the available genetic markers, microsatellites are recognized as an essential tool in population studies (Han et al., 2012; Kim et al., 2013). We had recently isolated polymorphic microsatellite markers and showed that these markers possessed the potential to characterize the genetic diversity and analyze the population structure of $H$. nitens (An et al., 2014). In the present study, we used 12 polymorphic nuclear microsatellite DNA loci to analyze the possible differences in the genetic variability between the wild and hatchery-produced populations of short barbeled grunter from Korea.

The main goal of this preliminary study was to evaluate the putative genetic changes in short barbeled grunter samples from a hatchery in Buan, Korea and to compare the results obtained with those of the wild population. These data are necessary for establishing and maintaining cultivated stocks toward conservation of the genetic diversity and for facilitating sustainable fry production.

\section{MATERIAL AND METHODS}

\section{Sample collection and DNA extraction}

Samples of fin-clip tissue $\left(\sim 1 \mathrm{~cm}^{3}\right)$ were obtained from the wild short barbeled grunter $(\mathrm{N}=25)$ caught from the western coastal area of Korea (Buan and Seocheon) through direct sampling in 2013. Hatchery stock was the progeny of broodstock reared at the West Sea Fisheries Research Institute of the National Fisheries Research and Development Institute in Buan, Korea which is the government-sponsored hatchery. Unfortunately, there are not records available regarding details of the parents used for the founding of this hatchery strain. At this facility, 50 individuals of the offspring short barbeled grunters produced in 2009 were randomly sampled in 2013.

Caudal fin or muscle samples from each Korean short barbeled grunter were clipped and immediately preserved in $99.9 \%$ ethanol until DNA extraction.

\section{Microsatellite genotyping}

Total genomic DNA was extracted from each sample by using the MagExtractorGenomic DNA Purification Kit (Toyobo, Japan) on the MagExtractor MFX-2100 Automated DNA Extraction System (Toyobo). The extracted genomic DNA was stored at $-20^{\circ} \mathrm{C}$ until microsatellite genotyping analysis.

We genotyped all samples at 12 polymorphic microsatellite loci (An et al., 2014). With the exception of KHn 19 (PIC $=0.485)$, all loci showed $>0.5$ polymorphism information content (PIC) values. The 5'-end of the forward primer of each set of primers was labeled with a fluorescent dye (6-FAM, HEX, or NED; Applied Biosystems, USA; Table 1). Polymerase chain reaction (PCR) amplification of the 12 microsatellite loci was performed in a 10- $\mu \mathrm{L}$ reaction solution containing 10-50 ng DNA, 1X ExTaq buffer, $0.2 \mathrm{mM}$ deoxynucleotides (dNTPs), $10 \mathrm{pM}$ of each primer, and $0.25 \mathrm{U}$ Taq DNA polymerase (TaKaRa, Japan) in the RTC 200 Thermal Cycler (MJ Research, USA). The amplification protocol consisted of an initial denaturation for $11 \mathrm{~min}$ at $95^{\circ} \mathrm{C}$, followed by 35 cycles of $1 \mathrm{~min}$ at $94^{\circ} \mathrm{C}, 1 \mathrm{~min}$ at $57^{\circ} \mathrm{C}$, and $1 \mathrm{~min}$ at $72^{\circ} \mathrm{C}$, with a final extension step of $5 \mathrm{~min}$ at $72^{\circ} \mathrm{C}$. For genotyping, $1 \mu \mathrm{L}$ of the 
PCR product was combined with formamide and a size standard, GeneScan-400HD [ROX] (Applied Biosystems) and electrophoresed by using the ABI3130 DNA Sequencer (Applied Biosystems). The fluorescent DNA fragments were analyzed by the GeneScan (version 3.7) and the Genotyper (version 3.7) software (Applied Biosystems).

Table 1. Twelve microsatellite loci sequences of Korean short barbeled grunter (Hapalogenys nitens) used in this study, and the core repeats and polymorphism information contents (PIC) used for polymerase chain reaction amplification.

\begin{tabular}{|c|c|c|c|c|}
\hline Locus & Primer sequence $\left(5^{\prime}-3^{\prime}\right)$ & Repeats & PIC & Accession No. \\
\hline KHn 3 & $\begin{array}{l}\text { F: ATCCACCACAACGATCGTTT } 6 \text { fam } \\
\text { R: TAAGAGTTGACCCCTCTGCA }\end{array}$ & $(\mathrm{AT})_{9}$ & 0.911 & KF170233 \\
\hline KHn 6 & $\begin{array}{l}\text { F: AGAAGCTGACCACAAACCAA ned } \\
\text { R: TGATGCTGGTGATGTAAGGG }\end{array}$ & $(\mathrm{GT})_{9}$ & 0.678 & KF170236 \\
\hline KHn 7 & $\begin{array}{l}\text { F: AAACTTCCAGTGACGAAGCT } \mathbf{6 f a m} \\
\text { R: ATTCACTGATGAGGCGTTCC }\end{array}$ & $(\mathrm{AT})_{9}$ & 0.584 & KF170237 \\
\hline KHn 11 & $\begin{array}{l}\text { F: TTTTGTGATGAGCGACCACT ned } \\
\text { R: CAAGCAGAGACAGTCATCCC }\end{array}$ & $(\mathrm{GT})_{9}$ & 0.700 & KF170241 \\
\hline KHn 12 & $\begin{array}{l}\text { F: AACTCCAGTGACGAAGCTAC ned } \\
\text { R: ATTCACTGATGAGGCGTTCC }\end{array}$ & $(\mathrm{AT})_{9}$ & 0.563 & KF170242 \\
\hline KHn 15 & $\begin{array}{l}\text { F: ATGCCATCAAAGAGCCTCAG hex } \\
\text { R: CCAGCTCGTCTTGTTCATCA }\end{array}$ & $(\mathrm{GGT})_{8}$ & 0.823 & KF170245 \\
\hline KHn 16 & $\begin{array}{l}\text { F: CTGAGATGATGCCGTGTTGA hex } \\
\text { R: TTCGTTTCCTTCATGCAGGA }\end{array}$ & $(\mathrm{AGC})_{9}$ & 0.517 & KF170246 \\
\hline KHn 17 & $\begin{array}{l}\text { F: AGTGCATGTTCTAACGCTGT hex } \\
\text { R: GTGCAGCTTCTGACTCATCA }\end{array}$ & $(\mathrm{GTT})_{9}$ & 0.591 & KF170247 \\
\hline KHn 18 & $\begin{array}{l}\text { F: CATGTGAGGGACGATAGCTG hex } \\
\text { R: GTTTCCACCCCACCAAGAAT }\end{array}$ & $(\mathrm{ATT})_{9}$ & 0.658 & KF170248 \\
\hline KHn 19 & $\begin{array}{l}\text { F: AATGCAGAAACTAGCGAGGG ned } \\
\text { R: GGAGTAAAGGCCGTATCTCG }\end{array}$ & $(\mathrm{GCT})_{9}$ & 0.485 & KF170249 \\
\hline KHn 21 & $\begin{array}{l}\text { F: CATCAAGACCGACTGACAGG } \mathbf{6} \mathbf{f a m} \\
\text { R: TGTACAGCGACAACACAACA }\end{array}$ & $(\mathrm{ATC})_{9}$ & 0.872 & KF170251 \\
\hline KHn 23 & $\begin{array}{l}\text { F: ACAGCAGGTCCGATTTTTGA hex } \\
\text { R: TTTGCCCATGACAAACTCCA }\end{array}$ & $(\mathrm{AGAT})_{9}$ & 0.524 & KF170253 \\
\hline
\end{tabular}

Primers were 5 'end labeled with the indicated dye (bold).

\section{Population comparison}

Individual genotypes were scored using the GeneMapper (version 4.0; Applied Biosystems) with a size standard and an internal control for allele calling; each allele was coded according to its size in nucleotide base pairs (bp). A panel that included all of the alleles detected in the 75 individuals was created for each locus. Possible null alleles and genotyping errors caused by stuttering and/or large-allele dropout were tested using MICROCHECKER (1000 randomizations) (Van Oosterhout et al., 2004). Scoring and human error were estimated by duplicate analyses. The genetic diversity of each sample was evaluated using the number of alleles $\left(N_{\mathrm{A}}\right)$, the size range of an allele in bp (S), the number of observed unique alleles $(U)$, the observed heterozygosity $\left(H_{\mathrm{O}}\right)$, the expected heterozygosity $\left(H_{\mathrm{E}}\right)$, and the polymorphic information content (PIC) calculated by using the CERVUS version 3.03 (Kalinowski et al., 2007). Differences in the genetic diversity parameters were identified by a nonparametric analysis (Wilcoxon signed-rank test; Wilcoxon, 1945). The allelic richness $\left(A_{\mathrm{R}}\right)$ as a standardized measure of the number of alleles per locus was corrected for the smallest sample size $(\mathrm{N}=30)$ by the rarefaction method of the FSTAT version 2.9.3.2 (http:// www2.unil.ch/popgen/softwares/fstat.htm). Linkage disequilibrium to determine the extent of distortion from the independent segregation of loci and deviations from the Hardy-Weinberg 
equilibrium (HWE) using the inbreeding coefficients $\left(F_{\text {IS }}\right.$; Weir and Cockerham, 1984) were tested with GENEPOP'007 (Rousset, 2008), and the significance levels were adjusted for multiple tests by using the sequential Bonferroni correction (Rice, 1989).

The extent of population subdivision was examined by calculating the global multilocus $F_{\mathrm{ST}}$ (Weir and Cockerham, 1984) and $R_{\mathrm{ST}}$ values (1000 permutations; Rousset, 1996). The indices of the pairwise $F_{\mathrm{ST}}$ values, based on an infinite allele model (IAM), and $R_{\mathrm{ST}}$ values, based on a stepwise mutation model (SMM), were calculated by using ARLEQUIN ver. 3.0 (Excoffier et al., 2005). A log-likelihood G test (Goudet et al., 1996) using GENEPOP'007 was employed to determine whether the allelic and genotypic distributions were identical between the 2 populations. The significances of $\mathrm{P}$ values across all loci for the 2 populations were determined by Fisher's probability combination test and evaluated following the sequential Bonferroni adjustment of critical probabilities (Rice, 1989). For the analysis of molecular variance (AMOVA; Excoffier et al., 1992), components of variance for both within and between populations based on the IAM were estimated by using ARLEQUIN ver. 3.0. The significance of AMOVA components was tested using 1000 permutations.

\section{RESULTS}

\section{Genetic diversity}

Two wild and hatchery-produced populations of $H$. nitens (total, $\mathrm{N}=75$ ) were screened for genetic variations at 12 polymorphic microsatellite loci. The 12 primer sets yielded variable profiles, and reruns were performed on 8 individuals from each of the sample sets to ensure reproducible allele scoring. No significant differences were observed among the profiles, indicating that genotyping errors did not affect allele scoring. The amplification of the 2 short barbeled grunter populations yielded $95-99 \%$ allele score in a single run (data not shown). Individual genotypes that were not scored in the first PCR assay were obtained after an additional PCR run, which reduced the likelihood of the results being affected by poor DNA quality. The MICRO-CHECKER analysis showed that 2 loci, KHn 3 and KHn 19, may have been influenced by 1 or more null alleles in the wild population, but no locus was affected by null alleles in both the samples. Therefore, all loci were used for subsequent analyses. None of the 12 loci exhibited highly significant linkage disequilibrium.

All 12 microsatellite loci were polymorphic in the 2 samples of short barbeled grunter, and the level of polymorphism varied among the loci. Specifically, KHn 3 and KHN 21 displayed greater allelic diversity as well as higher levels of heterozygosity. The measures of genetic diversity for each population, as calculated from the observed allele distribution, are presented in Table 2. The amplification of 75 individuals from 2 samples generated 91 alleles over the 12 loci, ranging from 3 alleles at locus KHn 19 to 17 alleles at locus KHn 3, with an average of 7.58 alleles per locus. Neither population had a diagnostic allele. A moderate-tohigh degree of polymorphism was detected per locus with PIC values of 0.388-0.902 (Table 2 ). The average gene diversity varied from 0.551 to 0.857 and the average heterozygosity ranged from 0.480 to 0.880 .

The difference in the genetic diversity was also reflected in the wild and hatcheryproduced samples. Allele frequencies at all 12 selected loci in each sample are presented in Figure 1, revealing the differences between the samples. Significantly greater number of al- 
leles were found in the wild population $(\mathrm{N}=89$, average $=7.42)$ than in the hatchery-produced population $(\mathrm{N}=45$; average $=3.75)($ Wilcoxon signed-rank test; $\mathrm{P}<0.05)$. The overall allelic richness varied from 3.00 to 13.53 (Table 2), with the wild population showing significantly higher allelic richness than the hatchery-produced population (average allelic richness: 7.42 vs 3.66) (Wilcoxon signed-rank test; $\mathrm{P}<0.05$ ). Forty-eight alleles were found to be unique to a single population (Table 2), but the hatchery-produced population had only 2 unique alleles (46 vs 2). However, because different numbers of individuals were analyzed in each population, these results should be interpreted with caution.

\begin{tabular}{|c|c|c|c|c|c|c|c|c|c|c|c|c|c|c|}
\hline \multirow[t]{2}{*}{ Population (N) } & & \multicolumn{13}{|c|}{ Microsatellite loci } \\
\hline & & KHn 3 & KHn 6 & KHn 7 & KHn 11 & KHn 12 & KHn 15 & KHn 16 & KHn 17 & KHn 18 & KHn 19 & KHn 21 & KHn 23 & Mean \\
\hline \multirow{4}{*}{ Wild (25) } & $F_{\mathrm{ST}}$ & 0.038 & 0.227 & 0.081 & 0.059 & 0.020 & 0.032 & 0.010 & 0.055 & 0.038 & 0.144 & 0.167 & 0.088 & 0.088 \\
\hline & $N_{\mathrm{A}}^{\mathrm{ST}}$ & 17 & 8 & 5 & 6 & 5 & 8 & 5 & 8 & 7 & 3 & 14 & 3 & 7.42 \\
\hline & $A_{\mathrm{R}}$ & 17.00 & 8.00 & 5.00 & 6.00 & 5.00 & 8.00 & 5.00 & 8.00 & 7.00 & 3.00 & 14.00 & 3.00 & 7.42 \\
\hline & $S^{\mathrm{R}}$ & $310-360$ & $177-195$ & $282-290$ & $228-238$ & $280-288$ & $227-254$ & $233-254$ & $256-289$ & $234-261$ & $162-168$ & $304-352$ & $228-236$ & \\
\hline \multirow{9}{*}{ Hatchery (50) } & $U$ & 12 & 3 & 2 & 3 & 2 & 2 & 2 & 6 & 4 & 0 & 10 & 0 & 3.83 \\
\hline & $H_{\mathrm{E}}$ & 0.927 & 0.718 & 0.662 & 0.751 & 0.636 & 0.830 & 0.589 & 0.624 & 0.720 & 0.580 & 0.901 & 0.618 & 0.713 \\
\hline & $H_{\mathrm{O}}$ & 0.480 & 0.720 & 0.840 & 0.760 & 0.560 & 0.800 & 0.720 & 0.640 & 0.840 & 0.360 & 0.840 & 0.680 & 0.687 \\
\hline & PIC & 0.902 & 0.678 & 0.584 & 0.700 & 0.563 & 0.788 & 0.517 & 0.591 & 0.658 & 0.485 & 0.873 & 0.524 & 0.655 \\
\hline & $F_{\text {IS }}$ & $0.488^{*}$ & -0.003 & -0.276 & -0.012 & 0.122 & 0.037 & -0.229 & -0.025 & -0.171 & 0.385 & 0.069 & -0.103 & 0.026 \\
\hline & $N_{\mathrm{A}}$ & 5 & 5 & 3 & 3 & 3 & 6 & 3 & 3 & 3 & 3 & 4 & 4 & 3.75 \\
\hline & $A_{\mathrm{R}}$ & 5.00 & 4.72 & 2.99 & 2.97 & 2.99 & 5.51 & 2.99 & 3.00 & 3.00 & 3.00 & 3.75 & 3.94 & 3.66 \\
\hline & $S^{\mathrm{R}}$ & $316-352$ & $177-195$ & $286-290$ & $230-238$ & $284-288$ & $227-248$ & $233-239$ & $256-265$ & $234-249$ & $162-168$ & $316-340$ & $224-236$ & \\
\hline & $U$ & 0 & 0 & 0 & 0 & 0 & 0 & 0 & 1 & 0 & 0 & 0 & 1 & 0.17 \\
\hline \multirow{8}{*}{$\begin{array}{l}\text { Mean of all } \\
\text { population }\end{array}$} & $H_{\mathrm{E}}$ & 0.786 & 0.692 & 0.447 & 0.509 & 0.466 & 0.734 & 0.447 & 0.539 & 0.635 & 0.576 & 0.660 & 0.680 & 0.598 \\
\hline & $H_{\mathrm{O}}$ & 0.700 & 0.820 & 0.540 & 0.600 & 0.500 & 0.920 & 0.500 & 0.600 & 0.920 & 0.600 & 0.860 & 0.700 & 0.688 \\
\hline & PIC & 0.743 & 0.629 & 0.388 & 0.418 & 0.401 & 0.680 & 0.388 & 0.467 & 0.557 & 0.475 & 0.583 & 0.610 & 0.529 \\
\hline & $F_{\text {IS }}$ & $0.111^{*}$ & -0.187 & -0.210 & -0.180 & -0.074 & $-0.257^{*}$ & -0.120 & -0.115 & $-0.456^{*}$ & -0.042 & $-0.307^{*}$ & $-0.030^{*}$ & -0.156 \\
\hline & $N_{\mathrm{A}}$ & 11 & 6.5 & 4 & 4.5 & 4 & 7 & 4 & 5.5 & 5 & 3 & 9 & 3.5 & 5.58 \\
\hline & $A_{\mathrm{R}}$ & 11.00 & 6.36 & 4.00 & 4.49 & 4.00 & 6.76 & 4.00 & 5.50 & 5.00 & 3.00 & 8.88 & 3.47 & 5.54 \\
\hline & $H_{\mathrm{E}}$ & 0.857 & 0.705 & 0.555 & 0.630 & 0.551 & 0.782 & 0.653 & 0.582 & 0.678 & 0.578 & 0.781 & 0.649 & 0.667 \\
\hline & $H_{\mathrm{O}}$ & 0.590 & 0.770 & 0.690 & 0.680 & 0.530 & 0.860 & 0.610 & 0.620 & 0.880 & 0.480 & 0.850 & 0.690 & 0.688 \\
\hline
\end{tabular}

Single-locus $F_{\mathrm{ST}}, \mathrm{No}=$ number of samples; $N_{\mathrm{A}}=$ number of alleles per locus; $A_{\mathrm{R}}=$ allellic richness; $S=$ size in bp of alleles; $U=$ number of unique alleles; $H_{\mathrm{E}}=$ expected heterozygosity; $H_{\mathrm{O}}=$ observed heterozygosity; PIC = polymorphism information content; and inbreeding coefficient $\left(F_{\text {IS }}\right)$ are given for each population and locus. Calculations assume that individuals with one microsatellite band are homozygous for the allele. *Significant deviation from the HardyWeinberg equilibrium after Bonferroni correction (P, initial $\alpha=0.05 / 12=0.004)$.

In terms of heterozygosity, significant difference was detected in the expected heterozygosity between the 2 samples. The average expected heterozygosity was estimated at 0.598 in the hatchery-produced population. The corresponding estimate was 0.713 in the wild population (Table 2). Similar average observed heterozygosity values were detected in both populations. Inbreeding coefficients $\left(F_{\text {IS }}\right)$ varied among markers from -0.456 (KHn 18) to 0.111 (KHn 3) in the hatchery samples and from -0.276 (KHn 7) to 0.488 (KHn 3) in the wild samples. Average $F_{\text {IS }}$ for all markers was -0.156 in the hatchery sample and 0.026 in the wild sample.

Significant departures from HWE after Bonferroni correction $(\mathrm{P}<0.004)$ were found at 5 loci (KHn 3, KHn 15, KHn 18, KHn 21, and KHn 23) in the hatchery-produced population and at 1 locus (KHn 3 ) in the wild population, indicating that deviations from HWE were mainly due to heterozygote excess (Table 2). 

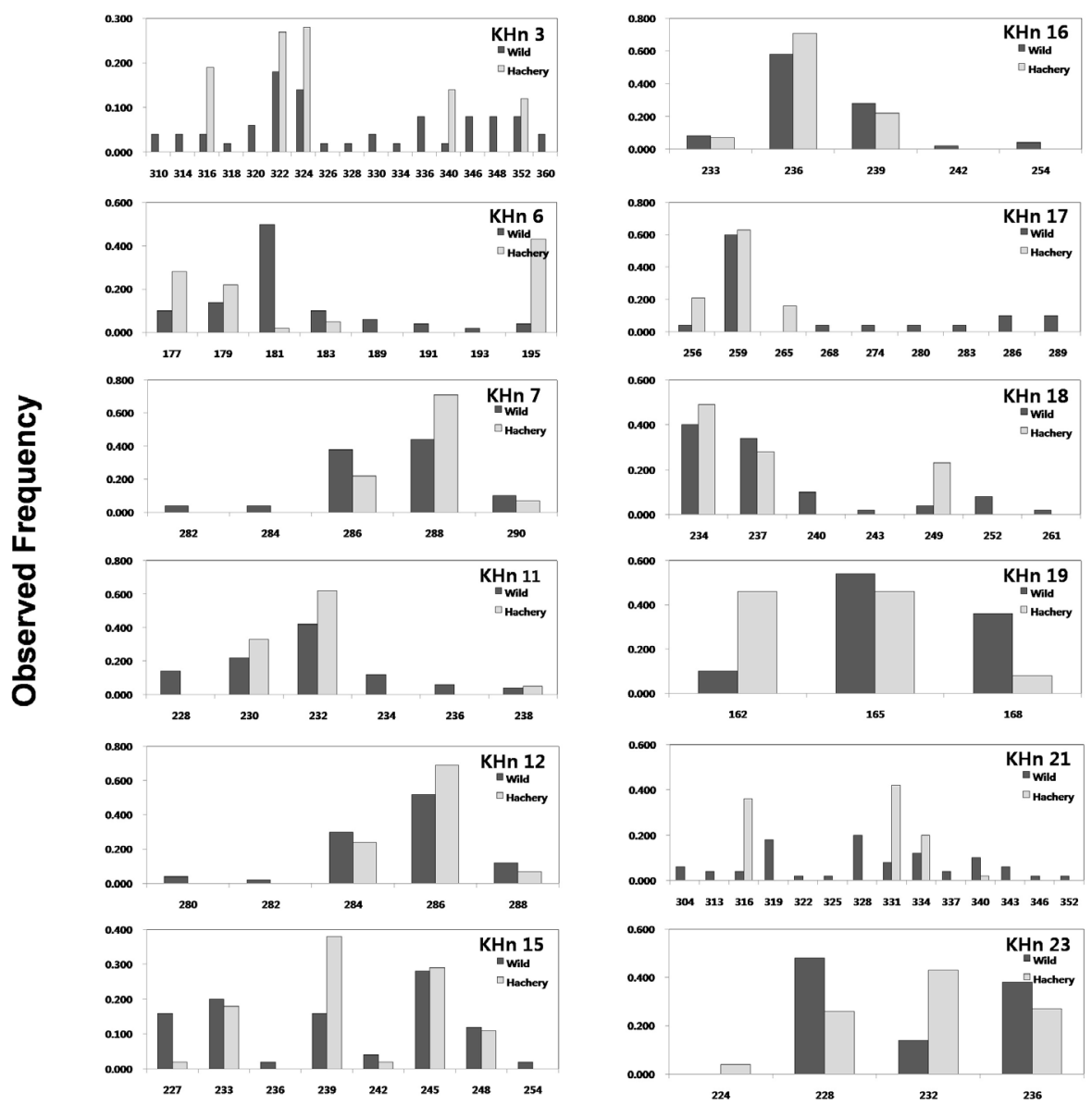

\section{Allele size (bp)}

Figure 1. Allele size frequency distributions of the 12 microsatellite loci in the wild and hatchery-produced Hapalogenys nitens populations used in this study.

\section{Population genetic differentiation}

Genetic differentiation between the wild and hatchery-produced populations of $H$. nitens was estimated by using $F_{\mathrm{ST}}$ and $R_{\mathrm{ST}}$ estimates. The global multilocus $F_{\mathrm{ST}}$, including all loci, was estimated to be $0.088(\mathrm{P}<0.01)$ and the $R_{\mathrm{ST}}$ value was $0.089(\mathrm{P}<0.01)$. These results indicate significant low genetic differentiation between the 2 populations. The AMOVA of all 12 microsatellites revealed similar results to the FSTAT analysis regarding variation within individuals of $98.82 \%(\mathrm{P}=0.931)$, among individuals within a population of $-7.56 \%(\mathrm{P}=0.997)$, and among populations of $8.75 \%(\mathrm{P}=0.000)$. The AMOVA revealed significant genetic differentiation between the 2 sample sets, although the low genetic variation was explained by the "among populations" hierarchical level of $8.75 \%$. Thus, the low differentiation between the wild and hatchery-produced populations was supported by the AMOVA results (Table 3). 
Table 3. Analysis of molecular variance (AMOVA) of 12 microsatellite loci in the wild and hatchery-produced Hapalogenys nitens populations.

\begin{tabular}{|c|c|c|c|c|c|}
\hline Source of variation & d.f. & Sum of squares & Variance components & Percentage variation $(\%)$ & $P$ value \\
\hline Among populations & 1 & 27.847 & 0.36527 & 8.75 & 0.000 \\
\hline Among individuals with population & 73 & 255.140 & -0.31580 & -7.56 & 0.997 \\
\hline Within individuals & 75 & 309.500 & 4.12667 & 98.82 & 0.931 \\
\hline Total & 149 & 592.487 & 4.17614 & & \\
\hline
\end{tabular}

Genetic differentiation between the 2 populations was also observed following pairwise comparisons of allelic and genotypic frequencies. The comparisons revealed that, of the 24 pairs of locus-population cases, 18 were significantly different for both the allelic and genotypic frequencies after sequential Bonferroni corrections. The significant changes at most of the loci, except for 3 loci (KHn 12, KHn 15, and KHn 16) were observed in the allelic and genotypic frequencies between the 2 populations (Table 4 ).

\begin{tabular}{|c|c|c|c|}
\hline Locus & $P$ value (allelic frequencies) & Locus & $\mathrm{P}$ value (genotypic frequencies) \\
\hline KHn 3 & $0.000 *$ & KHn 3 & $0.000 *$ \\
\hline KHn 6 & $0.000^{*}$ & KHn 6 & $0.000 *$ \\
\hline KHn 7 & $0.003 *$ & KHn 7 & $0.002 *$ \\
\hline KHn 11 & $0.000 *$ & KHn 11 & $0.000 *$ \\
\hline KHn 12 & 0.047 & KHn 12 & 0.062 \\
\hline KHn 15 & 0.006 & KHn 15 & 0.004 \\
\hline KHn 16 & 0.095 & KHn 16 & 0.087 \\
\hline KHn 17 & $0.000 *$ & KHn 17 & $0.000 *$ \\
\hline KHn 18 & $0.000^{*}$ & KHn 18 & $0.000 *$ \\
\hline KHn 19 & $0.000 *$ & KHn 19 & $0.000 *$ \\
\hline KHn 21 & $0.000^{*}$ & KHn 21 & $0.000 *$ \\
\hline KHn 23 & $0.000 *$ & KHn 23 & $0.001 *$ \\
\hline
\end{tabular}

The probability values of homogeneity of allelic and genotypic frequency distributions (P) estimated by a test analogous to the Fisher exact test by the Markov-chain method are shown; wide significance levels were applied using the sequential Bonferroni technique $(k=12)$. *Significance was set at $\mathrm{P}<0.004$.

\section{DISCUSSION}

In this study, genetic variation within the wild population of short barbeled grunter (mean $N_{\mathrm{A}}=7.42$, mean $H_{\mathrm{E}}=0.713$ ) was lower than that reported for other marine fish species (mean $N_{\mathrm{A}}=19.96 \pm 6.6$, mean $H_{\mathrm{E}}=0.77 \pm 0.19$ averaged from 12 species) (DeWoody and Avise, 2000). Because the allele number is positively related to the sample size as well as to the mutation rates at the polymorphic loci, the number of alleles observed at all 12 loci in this study is related to the relatively small size of the samples examined (Liu et al., 2009). Similar genetic variability has been reported for some other marine fish species (An et al., 2011a; Wang et al., 2011), suggesting that these polymorphic microsatellite loci were sufficient to reveal the intraspecific diversity among Korean short barbeled grunter.

When the level of diversity in the hatchery-produced population was compared with that of the wild population, significant differences were noted in the average number of alleles per locus and the average expected heterozygosity (Wilcoxon signed-rank test; $\mathrm{P}<0.05$ ). De- 
spite that several short barbeled grunter samples were analyzed from the hatchery-produced population, a $50.7 \%$ average reduction of alleles per locus and a $95.6 \%$ average reduction of unique alleles per locus as well as a $16.1 \%$ average reduction of expected heterozygosity were observed. This dramatic reduction in the genetic variability in the hatchery-produced population was consistent with the previous report that, in hatchery strains, the probability of the loss of rare alleles is high (Allendorf, 1986; Hutchings and Fraser, 2008). Tessier et al. (1997) reported an extreme case in which stocked offspring caused a major genetic drift and a $50 \%$ reduction in the effective population size of a wild Atlantic salmon population. In this past report, the cause of reduction of genetic variability was inferred to be lesser number of parents contributing to the hatchery population than the total natural population available. The loss of alleles is more important than the change in allele frequencies, because the latter may again change due to random drift, whereas a lost allele cannot be recovered, in which genetic factors are of vital importance for the production of high-quality seed for marine animals. An obvious degeneration of characteristics has been reported in the cultured fish stock, where the cultured fish does not reach full size, although they mature at an earlier age and have reduced resistance against diseases (Fang et al., 2000). Thus, the production of progeny should be based on well-organized broodstock management strategies. Furthermore, the use of hatchery-produced fish for artificial reproduction may have unintentional negative effects on the genetic variability of the broodstock for the production of high-quality offspring (Allendorf and Ryman, 1987). Parental similarity is negatively related to adult reproductive success and, wherever the sample sizes are large, the relationships become significantly negative (Amos et al., 2001). The protection of genetic characteristics of the cultured stock should be considered in artificial reproduction.

Significant deviations from HWE were observed in the hatchery-produced stock and in the wild population examined. These departures resulted from a deficit in heterozygosity in both the populations, and excess heterozygosity was mainly detected in the hatchery population. In the wild population, heterozygote deficit can be explained by several factors, such as the presence of unrecognized null alleles, natural selection acting on genetic markers, mating among relatives, the reduction of heterozygosity in a population caused by a subpopulation structure known as the Wahlund's effect, or a combination of these factors. In the present case, null allele was observed in the microsatellite locus KHn 3 and some form of assortative mating probably caused the deviation in the wild population. The importance of null allele as an explanation for heterozygote deficiency has been previously discussed for marine fish (Callen et al., 1993; De Sousa et al., 2005). In addition, the small effective population size of Korean short barbeled grunter together with the social behavior and heavy fishing activity may result in some marine species becoming exceptionally vulnerable to inbreeding (Hoarau et al., 2005). Hence, the heterozygote deficits observed in this study may have arisen, at least in part, from inbreeding. In hatchery populations, heterozygote deficiency is commonly caused by the limited number of founders, inbreeding, or both (Kohlmann et al., 2005; An et al., 2011b). This deficit may also be attributed to improper domestication processes occurring in the hatchery populations. In this study, 4 of the 5 significant HWE deviations in the hatchery-produced stock revealed a heterozygote excess. Heterozygote excess in the population is not as common as the heterozygote deficiency, although this point has not been fully explored theoretically. A decrease in the effective population size of Korean short barbeled grunter can result in the reduction in the population of homozygotes because the sampling bias of alleles can result from the small number of parents and the differences in the allele frequencies between the 
sexes (Fujio et al., 1985; Spencer et al., 2000). Hence, a decrease in the effective population size may play a contributory role to the heterozygote excess observed in this study.

The significant differentiation between the 2 populations, particularly in the number of private alleles is probably related to several factors such as habitat fragmentation, reduction in the effective number of contributing parents, and the effects of artificial selection on hatchery progeny. Hence, genetic drift has probably played an important role in the loss of genetic diversity and in the differentiation between wild and hatchery-produced populations. Because this study was limited by the number of populations screened, the genetic diversity parameters for each population and the HW disequilibrium at KHn 3 in the wild population may be explained by data obtained from additional sampling, both in terms of sample size and sampling locations. Access to such additional information would allow for a more comprehensive and precise genetic characterization of $H$. nitens.

A desirable characteristic of a sustainable fry production is the production of short barbeled grunter that is genetically similar to the wild population. The genetic integrity of wild population should be protected from the impact of hatchery production through a carefully planned broodstock management strategy. Unknown and known genetic changes and the possible loss of genetic variation in the wild and hatchery-produced populations should be monitored by using molecular tools such as nuclear DNA markers. This information will facilitate evaluation of the feasibility of the breeding program to maintain the genetic diversity of the wild population.

In summary, genetic diversity analyses revealed substantial changes in genetic variation and significant genetic differentiation between the wild and hatchery-produced populations of Korean short barbeled grunter. These results indicate that genetic drift may have negative effects on the reproductive capacity of the stock, because genetic factors are important in the production of high quality seed. Therefore, an adequate broodstock strategy may be necessary to guarantee the success of the complete aquaculture of short barbeled grunter in Korea. The information generated by this study may provide a useful genetic basis for future sustainable fry production planning and management of $H$. nitens in fisheries.

\section{ACKNOWLEDGMENTS}

Research supported by the National Fisheries Research and Development Institute (NFRDI; contribution \#RP-2013-BT-008). The views expressed herein are those of the authors and do not necessarily reflect the views of NFRDI.

\section{REFERENCES}

Allendorf FW (1986). Genetic drift and the loss of alleles versus heterozygosity. Zoo Biol. 5: 181-190.

Allendorf FW and Phelps SR (1980). Loss of genetic variation in a hatchery stock of cutthroat trout. Trans. Am. Fish. Soc. 109: 537-543.

Allendorf FW and Ryman N (1987). Genetic Management of Hatchery Stocks. In: Population Genetics and Fishery Management (Ryman N and Utter F, eds.). Washington Sea Grant, Seattle, 141-159.

Amos W, Wilmer JW, Fullard K, Burg TM, et al. (2001). The influence of parental relatedness on reproductive success. Proc. Biol. Sci. 268: 2021-2027.

An HS, Byun SG, Kim YC, Lee JW, et al. (2011a). Wild and hatchery populations of Korean starry flounder (Platichthys stellatus) compared using microsatellite DNA markers. Int. J. Mol. Sci. 12: 9189-9202.

An HS, Kim EM, Lee JH, Noh JK, et al. (2011b). Population genetic structure of wild and hatchery black rockfish Sebastes inermis in Korea, assessed using cross-species microsatellite markers. Genet. Mol. Res. 10: 2492-2504. 
An HS, Kang HW, Han HS, Park JY, et al. (2014). Isolation and characterization of 26 novel polynucleotide microsatellites from short barbeled grunter (Hapalogenys nitens) for genetic analysis. Conserv. Genet. Resour. 6: 669-672.

Callen DF, Thompson AD, Shen Y, Phillips HA, et al. (1993). Incidence and origin of "null" alleles in the (AC)n microsatellite markers. Am. J. Hum. Genet. 52: 922-927.

Choi CG and Kim JM (2012). Detection of Laminariaceae species based on PCR by family-specific ITS primers. Fish. Aquat. Sci. 15:157-162.

De Sousa SN, Finkeldey R and Gailing O (2005). Experimental verification of microsatellite null alleles in Norway spruce (Picea abies [L.] Karst.): implications for population genetic studies. Plant Mol. Biol. Rep. 23: 113-119.

DeWoody JA and Avise JC (2000). Microsatellite variation in marine, freshwater and anadromous fishes compared with other animals. J. Fish Biol. 56: 461-473.

Excoffier L, Smouse PE and Quattro JM (1992). Analysis of molecular variance inferred from metric distances among DNA haplotypes: application to human mitochondrial DNA restriction data. Genetics 131: 479-491.

Excoffier L, Laval G and Schneider S (2005). Arlequin (version 3.0): an integrated software package for population genetics data analysis. Evol. Bioinform. Online 1: 47-50.

Fang YQ, Weng YZ and Zhou J (2000). Study on early gonadal maturation in cultured large yellow croaker, Pseudosciaena crocea. J. Ocaeanogr. Taiwan Strait. 19: 494-496.

Fujio Y, Sasaki N, Sasaki M and Koganezawa A (1985). Genetic aspect of natural and released population of plaice. Bull. Tohoku Reg. Fish. Res. Lab. 47: 51-57.

Goudet J, Raymond M, de-Meeus T and Rousset F (1996). Testing differentiation in diploid populations. Genetics 144: 1933-1940.

Han HS, Nam BH, Kang JH, Kim YK, et al. (2012). Genetic variation in wild and cultured populations of the sea squirt Halocynthia roretzi inferred from microsatellite DNA analysis. Fish. Aquat. Sci. 15: 151-155.

Hoarau G, Boon E, Jongma DN, Ferber S, et al. (2005). Low effective population size and evidence for inbreeding in an overexploited flatfish, plaice (Pleuronectes platessa L.). Proc. Biol. Sci. 272: 497-503.

Hong SE, Kim JG, Yu JN, Kim KY, et al. (2012). Genetic variation in the Asian shore crab Hemigrapsus sanguineus in Korean coastal waters as inferred from mitochondrial DNA sequences. Fish. Aquat. Sci. 15: 49-56.

Hutchings JA and Fraser DJ (2008). The nature of fisheries- and farming-induced evolution. Mol. Ecol. 17: 294-313.

Johnson GD and Gill AC (1998). Encyclopedia of Fishes (Paxton JR and Eschmeyer WN, eds.). Academic Press, San Diego, 184.

Kalinowski ST, Taper ML and Marshall TC (2007). Revising how the computer program CERVUS accommodates genotyping error increases success in paternity assignment. Mol. Ecol. 16: 1099-1106.

Kang HW, Jun JC, Kang DY, Jo KC, et al. (2009). Influence of low salinity and cold water temperature on the hatching, survival and growth of the offspring of grunt, Hapalogenys nitens. Kor. J. Ichthyol. 21: 158-166.

Kim WJ, Shin EH, Kong HJ, Nam BH, et al. (2013). Development of polymorphic microsatellite markers suitable for genetic linkage mapping of olive flounder Paralichthys olivaceus. Fish. Aquat. Sci. 16: 303-309.

Kohlmann K, Kersten P and Flajshans M (2005). Microsatellite-based genetic variability and differentiation of domesticated, wild and feral common carp (Cyprinus carpio L.) populations. Aquaculture 247: 253-266.

Lee HJ and Hur SB (2012). Comparison between phylogenetic relationships based on 18S rDNA sequences and growth by salinity of Chlorella-like species (Chlorophyta). Fish. Aquat. Sci. 15: 125-135.

Liu F, Xia JH, Bai ZY, Fu JJ, et al. (2009). High genetic diversity and substantial population differentiation in grass carp (Ctenopharyngodon idella) revealed by microsatellite analysis. Aquaculture 297: 51-56.

NFRDI (National Fisheries and Development Institute) (2004). Commercial Fishes of the Coastal and Offshore Waters in Korea. NFRDI, Busan.

Pan G and Yang J (2010). Analysis of microsatellite DNA markers reveals no genetic differentiation between wild and hatchery populations of Pacific threadfin in Hawaii. Int. J. Biol. Sci. 6: 827-833.

Rice WR (1989). Analyzing tables of statistical tests. Evolution 43: 223-225.

Rousset F (1996). Equilibrium values of measures of population subdivision for stepwise mutation processes. Genetics 142: $1357-1362$.

Rousset F (2008). genepop'007: a complete re-implementation of the genepop software for Windows and Linux. Mol. Ecol. Resour. 8: 103-106.

Sekino M, Hara M and Taniguchi N (2002). Loss of microsatellite and mitochondrial DNA variation in hatchery strains of Japanese flounder Paralichthys olivaceus. Aquaculture 213: 101-122.

Spencer CC, Neigel JE and Leberg PL (2000). Experimental evaluation of the usefulness of microsatellite DNA for detecting demographic bottlenecks. Mol. Ecol. 9: 1517-1528.

Tessier N, Bernatchez L and Wright JM (1997). Population structure and impact supportive breeding inferred from mitochondrial and microsatellite DNA analyses in land-locked Atlantic salmon Salmo salar L. Mol. Ecol. 6: 735-750. 
Van Oosterhout C, Hutchinson WF, Wills DPM and Shipley P (2004). MICRO-CHECKER: software for identifying and correcting genotyping errors in microsatellite data. Mol. Ecol. Notes 4: 535-538.

Wang L, Meng Z, Liu X, Zhang Y, et al. (2011). Genetic diversity and differentiation of the orange-spotted grouper (Epinephelus coioides) between and within cultured stocks and wild populations inferred from microsatellite DNA analysis. Int. J. Mol. Sci. 12: 4378-4394.

Weir BS and Cockerham CC (1984). Estimating F-statistics for the analysis of population structure. Evolution 38: 1358-1370. Wilcoxon F (1945). Individual comparisons by ranking methods. Biometrics Bull. 1: 80-83. 